Check for updates

The BMJ

Cite this as: $B M J 2020 ; 370: m 3607$ http://dx.doi.org/10.1136/bmj.m3607 Published: 16 September 2020
BMA ANNUAL REPRESENTATIVE MEETING

\section{Doctors call for action on racism in wake of covid-19 and death of George Floyd}

\section{Gareth lacobucci}

The UK government has a "moral imperative" to take firm action against racism and health inequalities that have been laid bare by the covid-19 pandemic and the Black Lives Matter movement, the BMA has urged.

The association's annual representative meeting, held virtually on 15 September, passed a motion requesting concrete actions to tackle racism in the NHS and at a broader societal level.

The meeting called for all NHS boards to reflect the ethnic make-up of the workforce of the organisation they manage, for more transparent recruitment and promotion systems in all NHS organisations, and for every person involved in NHS recruitment to receive training on diversity and unconscious bias.

The NHS must also greatly improve its recording and analysis of ethnicity and should develop a mentorship scheme for black, Asian, and minority ethnic managers and clinical leaders, the motion urged.

The meeting called on the government to increase funding for public health to tackle ethnic, geographic, and gender inequalities in the UK. And it urged specific action based on culturally sensitive research to tackle the health, social, and educational problems caused to ethnic minority schoolchildren and to make recommendations to reduce these inequalities.

\section{Barriers}

The BMA council chair, Chaand Nagpaul, said, "The covid-19 pandemic and the Black Lives Matter movement has clearly demonstrated the importance of addressing health inequalities and racism in the UK and the NHS.

"This is not just making a few small changes; this is about changing the entire system for the better. A change that will mean doctors in years to come will not face the same barriers as many others have and continue to face. The government has a moral imperative to address these inequalities and act now."

Sathish Jayagopal, a surgeon from the BMA's Salisbury division who proposed the motion, said that the death of George Floyd in Minneapolis, USA, had “made the world shout out, 'enough is enough,' and it’s time to change."

He added, "Racism is sometimes so common around us that we are accepting it as the norm. The boards of NHS trusts should reflect the ethnic make-up of the workforce of the organisations which they manage. This is not just about doing or saying something derogatory. It is also stereotyping, prejudgment, and bias that exists."

Sai Pillarisetti, a medical student speaking in favour of the motion, said, "I strongly believe that unconscious bias training should be given greater importance in all aspects of medicine, and more specifically, be substantially integrated into medical schools' curricula.

"This will ensure that the next generation of newly qualified doctors are aware of the unconscious bias and, equally, [are] better equipped to recognise it taking place. I strongly believe that this step would go a long way in reducing inequality." 